\title{
Perception Driven From Farmers' Socio-economic Characteristics Towards Tackling Climate Change
}

\author{
Mpho Tshikororo ${ }^{1}$, Katlego Thaba ${ }^{1}$, Tshimangadzo Ashely Nefale ${ }^{1} \&$ Mashudu Tshikororo ${ }^{2}$ \\ ${ }^{1}$ School of Agriculture, Department of Agricultural Economics and Agribusiness, University of Venda, Limpopo, \\ South Africa \\ ${ }^{2}$ School of Agriculture, Institute of Rural Development, University of Venda, Limpopo, South Africa \\ Correspondence: Mpho Tshikororo, School of Agriculture, Department of Agricultural Economics and \\ Agribusiness, University of Venda, Private Bag X 5050, Thohoyandou 0950; Limpopo, South Africa. Tel: \\ 27-159-628-712. E-mail: mpho.tshikororo@univen.ac.za
}

Received: March 11, 2021

Accepted: April 21, $2021 \quad$ Online Published: May 15, 2021

doi:10.5539/jas.v13n6p41

\author{
URL: https://doi.org/10.5539/jas.v13n6p41
}

\begin{abstract}
Climate change is part of us and we are unlikely to avoid its impact. Impacts of climate change are severely felt within the agricultural sector, the division that strives to ensure food and nutrition security and contribute towards sustainable development in many of the developing countries. The only way farmers can survive in the face of climate change is through adaptation, a phenomenon that needs collaborative efforts. One of the critical driving factors of climate change adaptation is farmers' perception towards tackling it, the focus of this paper. The main objective of this paper was to assess farmers' perception towards tackling climate change. The population of the study was emerging farmers drawn from five districts of the Limpopo province, South Africa. The study used a two-stage cluster sampling technique to select a sample size of 206 emerging farmers. The dependent variable of the study was farmers' perception about tackling climate change while the explanatory variables consisted of their socio-economic characteristics such as age, gender, farming experience and level of education. Discriminant Analysis was used to draw comparison between groups of farmers who perceived that climate change can be tackled and those who believed it cannot be. The results showed that socio-economic characteristics such as formal education, agricultural education, age group, farming experience and off-farm occupation significantly contributed towards farmers' perception regarding tackling of climate change. Therefore, the study recommended that stakeholders should facilitate linkage of farmers with varied sources of support.
\end{abstract}

Keywords: adaptation to climate change, agriculture, South Africa, discriminant analysis, emerging farmers

\section{Introduction}

Developing countries are vulnerable to climate change and variability, although they are not affected equally (IPCC, 2007). Climate change remains to be one of the global tests against improved sustainable livelihood particularly through its proven negative impacts on agricultural productivity (Pye-Smith, 2011). Climate change continues to significantly impact agricultural performance (Adeagbo et al., 2021). In Africa, both food and nutrition insecurities continues to be alarming as its agricultural productivity is severely affected by climate change (Ziervogel et al., 2006). Farmers in Africa are likely to experience tragic crop failures, reduced agricultural productivity and diseases outbreak through the impacts of climate change (Zoellick, 2009). Per IFAD (2010), it is likely not possible to avoid the impacts of climate change; and thus, vital to promote strategies which farmers and other stakeholders can use to tackle climate change within their unit of operation. Farmers' perceptions of climate change seem to shape their behaviour to adapt and influence their selections of adaptation to climate change (Nguyen et al., 2016).

Similarly, it has been noted that farmers' perceptions and their interpretation have a significant impact towards adaptation climate change (Ndamani \& Watanabe, 2016). However, a study conducted by Niles et al. (2016) concluded that farmers' attitude and perception towards climate change do not correlate to their actual adoption. It has been noted that farmers' religious belief plays a vital role on their willingness to adapt to climate change and it is also believed to shape the adaptive capacity of communities in response to climate change (Murphy et al., 2016). Socio-cultural perception is also an influencer of farmers' decision to mitigate the impacts of climate change through adaptation (Nguyen et al., 2016). Though there are numerous determinants of farmers' 
adaptation to climate change, their perception towards it still forms the integral part of their responsive decision (Ramborun et al., 2020). Hence this paper addressed farmers' perception towards tackling of climate change as one of the critical determinants of climate change adaptation.

\section{Material and Method}

\subsection{Study Area}

The study was conducted in Limpopo province. Limpopo province is the fifth largest province among the nine provinces in South Africa. Per Statistics South Africa (2015), the population in Limpopo province was estimated to be 5,726,800 people. Furthermore, it is the northern-most province of South Africa and covers about 125,754 $\mathrm{km}^{2}$. Limpopo province shares international borders with Botswana, Zimbabwe and Mozambique (LTA, 2014). Limpopo province is divided into five municipal districts; Capricorn, Mopani, Sekhukhune, Vhembe and Waterberg; and 25 local municipalities. It is regarded as one of the leading regions for agricultural production such as livestock, fruits, vegetables, cereals and tea (LTA, 2014).

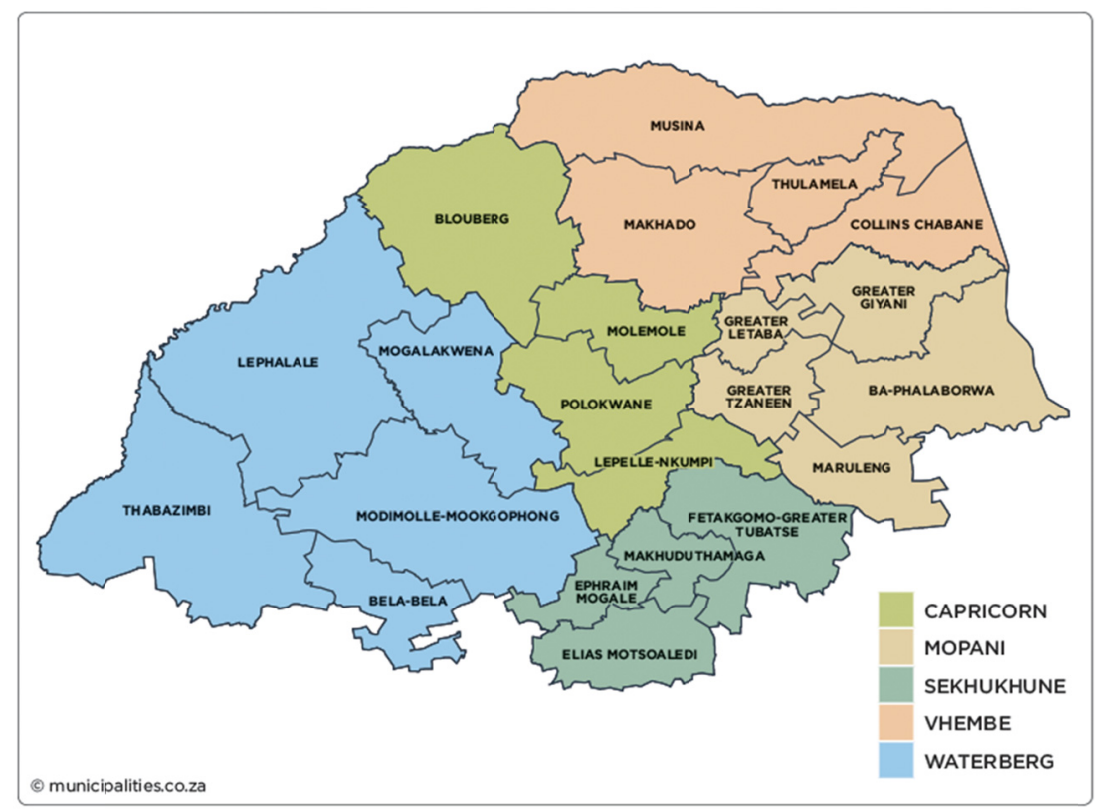

Figure 1. Limpopo province and local municipalities map

\subsection{Sampling Technique and Data Collection}

The population of 550 emerging farmers in Limpopo province was used for the study. The study employed a clustered systematic random selection technique to collect primary data. In this sampling technique, the researcher picks groups or clusters, and then from each cluster, the researcher selects individual subjects and further employ a systematic random sampling as it allows the researcher to add a degree of system or process into the random selection of subjects (Eplorable, 2009). Farmers from all five districts of the Limpopo province were proportionally selected for inclusion using the above clustered systematic random selection technique. Farmers were clustered firstly from five districts and further into local municipalities where they were systematically random sampled from each local municipality. A sample size of 206 emerging farmers was obtained from the population of 550. Face to face interviews were carried out with the participants whereby structured questionnaires were administered to them.

\subsection{Empirical Model}

Discriminant analysis (DA) method was used to analyse the data. Discriminant analysis was selected for its strength to draw differences between two or more groups (Rakgase, 2015). It was deemed suitable as it allows the researcher to determine meaningful differences that could exist between groups and identifying the discriminating power of each variable. The study used discriminant correspondence analysis based on the categorical explanatory variables. The discriminant function provided the best discrimination between the groups per the explanatory variables. The function used was: 


$$
\begin{gathered}
D_{i}=b_{0}+\sum_{k=1}^{p} b_{k} X_{k} \\
D_{i}=b_{1} X_{1}+b_{2} X_{2}+b_{3} X_{3}+\ldots+b_{k} X_{k}
\end{gathered}
$$

Where,

$D_{i}=$ The $i^{\text {th }}$ score on the discriminant function; $b_{k}=$ Discriminant coefficient estimated; $X_{k}=$ Explanatory variables.

The core advantage of the linear discriminant function is that its measure of predictive ability is in terms of the percent of cases that are correctly classified. Subsequently, the discriminant analysis was a fitting method for use in this study to identify characteristics of farmers of those who believe climate change can be tackled from those who do not hold the same view.

The specification of the model is as follows:

$$
D_{i}=b_{1} X_{1}+b_{2} X_{2}+b_{3} X_{3}+b_{4} X_{4}+b_{5} X_{5}+b_{6} X_{6}+b_{7} X_{7}+b_{8} X_{8}+b_{9} X_{9}+b_{10} X_{10}
$$

These variables are described in Table 1 and their expected impact is shown in a form of sign.

Table 1. Description of explanatory variables used in the discriminant analysis

\begin{tabular}{llll}
\hline Variable & Name description & Type of measure & Expected sign \\
\hline $\mathrm{X}_{1}$ & Marital Status & Dummy; $0=$ married, $1=$ not married & $-/+$ \\
$\mathrm{X}_{2}$ & Gender & Dummy; $0=$ female, $1=$ male & $-/+$ \\
$\mathrm{X}_{3}$ & Formal education & $0=$ no qualification, $1=$ primary, $2=$ secondary, $3=$ tertiary, $4=$ others & + \\
$\mathrm{X}_{4}$ & Agricultural Education & Dummy; $0=$ no agricultural education, $1=$ has agricultural education & + \\
$\mathrm{X}_{5}$ & Age group & $0=$ under $21,1=21-39,2=40-59,3=60$ and older & $-/+$ \\
$\mathrm{X}_{6}$ & Farming experience & $0=$ less than a year, $1=1-5,2=6-10,3=$ more than 10 years & + \\
$\mathrm{X}_{7}$ & Off-farm occupation & $0=$ employed, $1=$ self-employed & - \\
$\mathrm{X}_{8}$ & Off-farm income & $0=$ employed, $1=$ pension, $2=$ remittances, $3=$ others & - \\
$\mathrm{X}_{9}$ & Household size & $0=1-5,1=6-10,2=11-15,3=$ more than 15 & + \\
$\mathrm{X}_{10}$ & Monthly income & $0=$ less than R1000, $1=\mathrm{R} 1001-\mathrm{R} 3000,2=\mathrm{R} 3001-\mathrm{R} 5000,3=$ more than R5000 & + \\
\hline
\end{tabular}

Note. Dependent variable $=$ Can we tackle climate change $($ Yes $=0 ;$ No $=1)$.

\section{Results}

Table 2 presents the group means, including the pooled sample means of the variables employed on the analysis. Their significant difference levels are indicated by their P-values. While the comparison between the two groups is based on their means. The results showed that only $41 \%$ of farmers who participated in the study perceived that climate change may be tackled. The results showed that the following variables; level of formal education (X3), agricultural education (X4), age group (X5), farming experience (X6) and occupation (X7) of farmers are all statistically significant at $5 \%$ level of significance. Furthermore, the results show that farmers who perceived that climate change can be tackled are those with higher level of formal education than their counterparts; results which the study expected as shown in Table 1. Farmers who are in possession of formal agricultural education perceived that climate change cannot be tackled, this is contrary to what was expected from the study (Table 1). The results also revealed that farmers who falls within older age group are of the view that climate change cannot be tackled, same as farmers who possess higher farming experience. Lastly, the results of the study indicate that farmers with off-farm occupation perceived that climate change can be tackled. 
Table 2. Group means of variables employed in the analysis

\begin{tabular}{lllll}
\hline \multirow{2}{*}{ Variables } & \multicolumn{2}{c}{ Can we tackle climate change? } & \multirow{2}{*}{ All } & \multirow{2}{*}{ P-value } \\
\cline { 2 - 3 } & Yes & No & & \\
\hline$X_{1}$ & $0.36(0.482)$ & $0.31(0.459)$ & $0.33(0.471)$ & 0.496 \\
$X_{2}$ & $0.43(0.482)$ & $0.36(0.482)$ & $0.39(0.489)$ & 0.328 \\
$X_{3}$ & $1.30(1.297)$ & $0.91(1.199)$ & $1.07(1.251)$ & $0.028^{* *}$ \\
$X_{4}$ & $0.81(0.395)$ & $0.92(0.275)$ & $0.87(0.333)$ & $0.021^{* *}$ \\
$X_{5}$ & $1.96(0.813)$ & $2.25(0.826)$ & $2.13(0.831)$ & $0.016^{* *}$ \\
$X_{6}$ & $1.98(1.075)$ & $2.26(0.986)$ & $2.15(1.030)$ & $0.050^{* *}$ \\
$X_{7}$ & $1.32(1.328)$ & $0.95(1.278)$ & $1.10(1.308)$ & $0.045^{* *}$ \\
$X_{8}$ & $1.88(1.091)$ & $1.94(1.007)$ & $1.92(1.040)$ & 0.677 \\
$X_{9}$ & $0.81(0.630)$ & $0.82(0.617)$ & $0.82(0.621)$ & 0.909 \\
$X_{10}$ & $1.21(1.042)$ & $1.21(1.093)$ & $0.21(0.070)$ & 0.994 \\
Number of cases (n) & $\mathbf{8 4}$ & $\mathbf{1 2 2}$ & $\mathbf{2 0 6}$ & \\
\hline
\end{tabular}

Note. Standard deviations in brackets. ${ }^{* * *},{ }^{* *}, *$ Significant at $1 \%, 5 \%$, and $10 \%$ probability level, respectively.

Table 3 presents the results of the discriminant scores and the levels of the dependent variable are lowly correlated. The results indicated that eigen value was low (0.115), with an implication that groups differences were lower than within the group differences. Furthermore, Table 3 shows that Wilks' lambda scored a high value of 0.89 . This implies the high accuracy of discriminant model used as well as measuring the importance of the variables used. The Chi-square statistics was useful in testing the null hypothesis that the discriminant function had no discriminating ability. The null hypothesis was not rejected since the Chi-square (21.294) with degrees of freedom, $\mathrm{df}=10$, was significant at the $1 \%$ level of significance $(0.007)$. This further shows that the discriminant function used for the analysis was appropriate. \%Grouped cases correctly classified results, show the prediction accuracy of the model is $61.7 \%$, so it is evident that the discriminant function has high precision prediction, because in general the accuracy in over $50 \%$ is considered valid, as noted by Thaba et al. (2016). The standardized canonical discriminant coefficients of the independent variables showed that the variables that separated the two groups of farmers the most were: agricultural education (X4), age group (X5) and off farm income (X8).

Table 3. Standardized canonical discriminant function coefficients

\begin{tabular}{lll}
\hline Explanatory variable & Coefficient & Wilks' Lambda \\
\hline X1 & 0.013 & 0.998 \\
X2 & -0.214 & 0.995 \\
X3 & -0.295 & 0.977 \\
X4 & 0.481 & 0.974 \\
X5 & 0.568 & 0.972 \\
X6 & 0.205 & 0.981 \\
X7 & -0.468 & 0.981 \\
X8 & 0.404 & 0.999 \\
X9 & -0.218 & 1.000 \\
X10 & 0.092 & 1.000 \\
\hline Statistics & & \\
Eigen value & 0.115 & \\
Canonical correlation & 0.321 & \\
Walks' Lambda & 0.897 & \\
Chi-square & 21.294 & \\
df & 10 & \\
P-value & 0.007 & \\
\% grouped cases & $61.7 \%$ & \\
\hline
\end{tabular}




\section{Discussion}

Farmers who are aware or have heard about climate change are in a better position to adapt through various practices. The findings of the study revealed that farmers who perceived that climate change can be tackled (41\%) are fewer than those who were of the view that it cannot be tackled as they account to $59 \%$. The findings of the study revealed that farmers with formal education perceived that climate change can be tackled. Attaining a formal education gives any farmer an advantage to have a clear and a better understanding about climate change. The findings are in line with the study conducted by Al-Amin et al. (2020) who revealed that formal education of farmers has a positive impact towards tackling climate change as farmers with higher level of education were found to be even willing to pay for their own adaptation program. From the findings, farmers with formal education where of the view that climate change can be tackled and this could be because attaining formal education enhances farmers' options to adapt to climate change. This is consistent with the study conducted by Gebru et al. (2020) which discovered that farmer's education has a positive and significant influence on adoption of various climate change strategies such as crop varieties, diversification and soil and water conservation. Furthermore, farmers with higher educational level were found to be in a better position to adapt to climate change due to their knowledge and ability to access information on climate change and adaptation options (Ndamani \& Watanabe, 2016). The findings of the study revealed that farmers who are in position of agricultural education perceived that climate change cannot be tackled.

The findings are shaped by farmers' experience, as most farmers may find their agricultural education not effective or helpful towards climate change adaptation. This view is supported by a study conducted by Mogomotsi et al. (2020) who stated that farmers who usually have climate change adaptive strategies in place are those with a wealth of farming experience and they rely more on indigenous knowledge. The study further revealed that when farmers belong to a higher age group they believed that climate change cannot be tackled. Elderly farmers are rich in farming experience and over the years, they note farming practices that are more effective under various environmental conditions. These results are in line to that of the study conducted by Thinda et al. (2020), who revealed that younger farmers are more likely to adapt to climate change more than their counterparts possibly due to their willingness to try new methods. The findings of the study are also supported by Ali and Erenstien (2017) who also revealed that older farmers are reluctant to try new farming methods and thus have a negative impact towards adaptation. The findings of the study revealed that farmers with more of farming experience are of the view that climate change cannot be tackle. The contrary was expected from the study due to the common trend of farming experience being found to positively influence adaptation to climate change. Farmers accumulate knowledge on climatic conditions with time, hence it is expected that farming experience should effectively influence tackling climate change. A study conducted by Diallo et al. (2020) discovered that farming experience of farmers doesn't have a significant influence on the adoption of all adaptive strategies. This implies that farming experience can have both positive and negative impact towards the efforts to tackle climate change.

Lastly, the study revealed that farmers with off-farm occupation perceived that climate change can be tackled. Farmers with off-farm occupation are most likely to discover different options to adapt to climate change. This is in line with the findings of the study conducted by Thinda et al. (2020) who revealed that participating in off-farm income activities position farmers well to learn various technology adaptation opportunities. Securing off-farm occupation may also positively influence farmers' decision to adapt to climate change as it may enhance farmers' ability to finance the adaption process.

\section{Conclusion and Recommendations}

The study discovered that fewer farmers (41\%) professed that climate change can indeed be tackled. The study revealed that farmers with formal education and off-farm occupation perceived that climate change can be tackled. Furthermore, the study also revealed that older farmers, those with agricultural qualifications and more farming experience where of the view that climate change cannot be tackled. Therefore, the study recommends that various stakeholders should facilitate trainings on accessing various sources of information including that of climate change to farmers. Multimedia tools should be used to promote climate change awareness among farmers, particularly those in remote rural areas. Furthermore, climate change information should be made available to farmers in various platforms such as local radio stations, through extension officers, Farmers Day, workshops and networking sessions, using a simple language to understand. The study also recommends that farmers may be linked with various sources of support (government and private) as securing off-farm occupation helps farmers to fund their farming activities. Furthermore, it is recommended that experienced farmers may be assisted to blend their indigenous knowledge with recently developed climate change adaptive strategies. The study also recommends that elderly farmers be trained less demanding adaptive strategies so to enhance their 
willingness to tackle climate change. The study also recommends that agricultural qualifications should have climate change adaptation component as this will enhance adaptive capacity of agricultural qualification holders.

\section{Acknowledgements}

Financial assistance received from the University of Venda Research and Publication Committee and National Research Funds for this study, is highly appreciated. The authors would particularly like to thank all the 206 participants for their patient involvement in the survey interview.

\section{References}

Adeagbo, O. A., Ojo, T. O., \& Adetoro, A. A. (2021). Understanding the determinants of climate change adaptation strategies among smallholder maize farmers in South-West, Nigeria. Heliyon, 7(2), e06231. https://doi.org/10.1016/j.heliyon.2021.e06231

Al-Amin, A. Q., Masud, M. M., Sarkar, M. S. K., Leal Filho, W., \& Doberstein, B. (2020). Analysing the socioeconomic and motivational factors affecting the willingness to pay for climate change adaptation in Malaysia. International Journal of Disaster Risk Reduction, 50, 101708. https://doi.org/10.1016/j.ijdrr. 2020.101708

Ali, A., \& Erenstein, O. (2017). Assessing farmer use of climate change adaptation practices and impacts on food security and poverty in Pakistan. Climate Risk Management, 16, 183-194. https://doi.org/10.1016/j.crm. 2016.12.001

Diallo, A., Donkor, E., \& Owusu, V. (2020). Climate change adaptation strategies, productivity and sustainable food security in southern Mali. Climatic Change, 159, 309-327. https://doi.org/10.1007/s10584-02002684-8

Explorable. (2009). Retrieved February 4, 2021, from https:/explorable.com

Gebru, G. W., Ichoku, H. E., \& Phil-Eze, P. O. (2020). Determinants of smallholder farmers' adoption of adaptation strategies to climate change in Eastern Tigray National Regional State of Ethiopia. Heliyon, 6(7), e04356. https://doi.org/10.1016/j.heliyon.2020.e04356

IFAD. (2010). Livestock and climate change. IFAD publishers, Rome.

IPCC. (2007). Impacts, adaptations and vulnerability (4th Assessment Report). Cambridge University Press, Cambridge, UK.

LTA (Limpopo Travel Agency). (2014). Retrieved February 4, 2021, from http://www.golimpopo.com

Mogomotsi, P. K., Sekelemani, A., \& Mogomotsi, G. E. (2020). Climate change adaptation strategies of small-scale farmers in Ngamiland East, Botswana. Climatic Change, 159, 441-460. https://doi.org/10.1007/ s10584-019-02645-w

Murphy, C., Tembo, M., Phiri, A., Yerokun, O., \& Grummell, B. (2016). Adapting to climate change in shifting landscapes of belief. Climatic Change, 134(1-2), 101114. https://doi.org/10.1007/s10584-015- 498-8

Ndamani, F., \& Watanabe, T. (2016). Determinants of farmers' adaptation to climate change: a micro level analysis in Ghana. Scientia Agricola, 73(3), 201-208. https://doi.org/10.1590/0103-9016-2015-0163

Nguyen, T. P. L., Seddaiu, G., Virdis, S. G. P., Tidore, C., Pasqui, M., \& Roggero, P. P. (2016). Perceiving to learn or learning to perceive? Understanding farmers' perceptions and adaptation to climate uncertainties. Agricultural Systems, 143, 205-216. https://doi.org/10.1016/j.agsy.2016.01.001

Niles, M. T., Brown, M., \& Dynes, R. (2016). Farmer's intended and actual adoption of climate change mitigation and adaptation strategies. Climatic Change, 135(2), 277-295. https://doi.org/10.1007/s10584015-1558-0

Pye-Smith, C. (2011). Farming's climate-smart future: Placing agriculture at the heart of climate-change policy. Wageningen, Netherlands: CGIAR Research Program on Climate Change, Agriculture and Food Security (CCAFS) and the Technical Centre for Agricultural and Rural Cooperation (CTA).

Rakgase, M. A., \& Norris, D. (2015). Determinants of livestock farmers' perception of future droughts and adoption of mitigating plans. International Journal of Climate Change Strategies and Management, 7(2), 191-205.

Ramborun, V., Facknath, S., \& Lalljee, B. (2020). Moving toward sustainable agriculture through a better understanding of farmer perceptions and attitudes to cope with climate change. The Journal of Agricultural Education and Extension, 26(1), 37-57. https://doi.org/10.1080/1389224X.2019.1690012. 
Thaba, K., Anim, F. D. K., \& Tshikororo, M. (2016). Analysis of Factors Affecting Proper Functioning of Smallholder Agricultural Cooperatives in the Limpopo Province of South Africa. Journal of Human Ecology, 54(3), 150-157. https://doi.org/10.1080/09709274.2016.11906997

Thinda, K. T., Ogundeji, A. A., Belle, J. A., \& Ojo, T. O. (2020). Understanding the adoption of climate change adaptation strategies among smallholder farmers: Evidence from land reform beneficiaries in South Africa. Land Use Policy, 99, 104858. https://doi.org/10.1016/j.landusepol.2020.104858

Ziervogel, G., Nyong, A., Osman, B., Conde, C., Cortes, S., \& Dowing, T. (2006). Climate variability and change: implications for household food security. Assessments of Impacts and Adaptations to Climate Change (AIACC) Working Paper No. 20, January 2006. The AIACC Project Office, International START Secretariat, Washington DC, USA.

Zoellick, R. B. (2009). A Climate Smart Future. The Nation Newspapers (p. 18). Vintage Press Limited, Lagos, Nigeria.

\section{Copyrights}

Copyright for this article is retained by the author(s), with first publication rights granted to the journal.

This is an open-access article distributed under the terms and conditions of the Creative Commons Attribution license (http://creativecommons.org/licenses/by/4.0/). 